\title{
FURTHER TESTS OF STELLAR RADIOMETERS AND SOME MEASUREMENTS OF PLANETARY RADIA- TION.
}

\author{
By W. W. Coblentz.
}

ABSTRACT.

The purpose of the present paper is ( $\mathrm{I}$ ) to describe improvements in the radiometric apparatus used in measuring the heat radiated by celestial objects, (2) to give some preliminary measurements of the radiation emitted by planets, and (3) to describe the verification of the procedure used a year ago in determining stellar temperatures by means of spectral transmission screens.

By means of a $\mathrm{I}-\mathrm{cm}$ cell of water, the planetary radiation was separated from the solar radiation, and in this manner a measurement was obtained of the infra-red thermal radiation emitted by the planet.

It was found that the intensity of the planetary radiation increases with decrease in the density of the surrounding atmosphere, and in per cent of the total radiation emitted is as follows: Jupiter (0), Venus (5), Saturn (15), Mars (30), and the moon (80).

The intensity of the planetary radiation from the northern hemisphere of Mars was found to be less than from the southern hemisphere. All the measurements indicate an appreciable rise in the temperature of the Martian surface as a result of heating by solar radiation.

The spectral component radiation measurements made on the sun verify previous temperature measurements of stars (B. S. Sci. Papers, No. 438) which range from $3,000^{\circ}$ $\mathrm{K}$. for red (class M) stars to $12,000^{\circ} \mathrm{K}$. for blue (class B) stars.

\section{CONTENTS.}

Page.

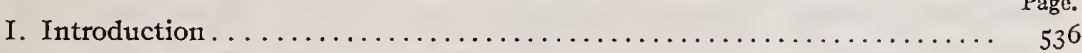

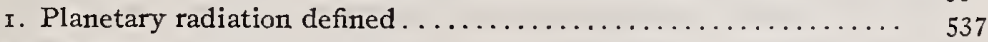

II. Apparatus and procedure . . . . . . . . . . . . . . . ${ }_{53} 8$

I. Description of the vacuum thermocouples used in the present work. 538

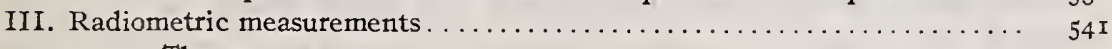

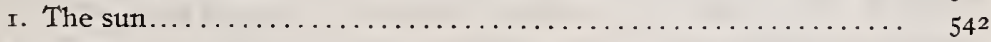

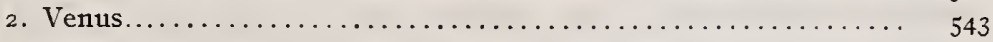

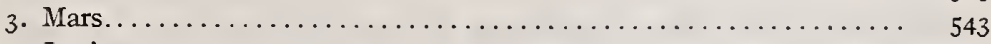

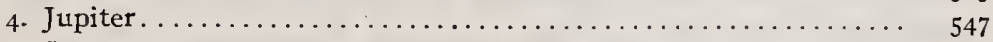

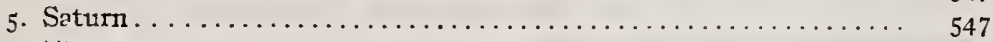

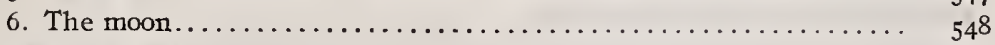

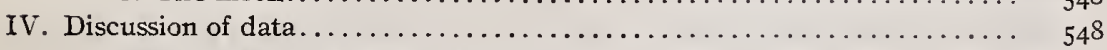

I. Planetary temperatures......................... 548

2. Selective reflection of solar radiation ................. 549

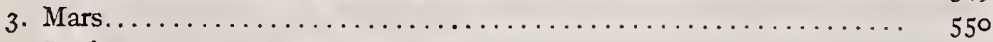

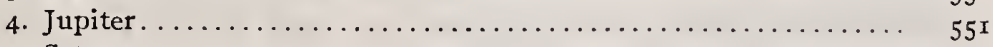

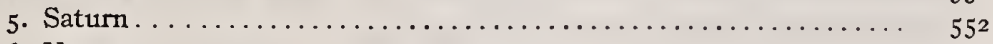

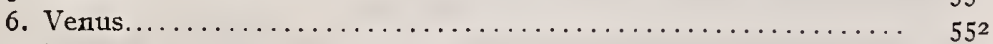

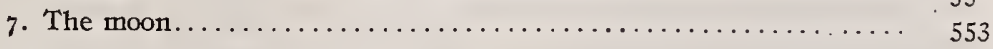

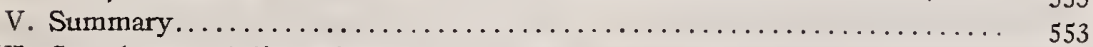

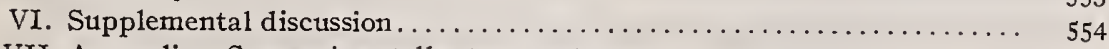

VII. Appendix-Concerning stellar temperatures. . . . . . . . . . . 557 


\section{INTRODUCTION.}

During the past summer, through the generosity of the Lowell Observatory, Flagstaff, Ariz., which financed this research, the writer was given further opportunity to continue his investigations of I92I, relating to instruments and methods of radiometry as applied to the measurement of stellar and planetary radiation. Dr. C. O. Lampland again kindly operated the telescope, and it is proposed to publish the complete results in a joint paper on the measurements of planetary radiation and their astronomical significance.

The purpose of the present paper is to describe improvement in the radiometric apparatus used and the results (of interest to physicists) of some preliminary measurements of planetary radiation as well as a verification of the measurements obtained a year ago in determining stellar temperatures by means of spectral transmission screens.

In this connection it is relevant to point out that the results obtained in mapping the spectral energy distribution of a star by means of a spectrobolometer may not be essentially different from those obtained by the use of transmission screens. For, as may be seen from inspection of photographs of stellar spectra, the spectrum of a star consists of a bright continuous background superposed upon a series of absorption (and in some cases bright emission) lines. Hence, unless a very large dispersion can be used, the spectrobolometer will merely bridge over wide regions of the spectrum containing bright and dark bands. The spectral transmission screen does practically the same thing, in the sense that it integrates the energy present in a certain spectral region (without indicating the amount lost in the spectral absorption lines) and has the advantage of utilizing perhaps 40 per cent of the total intensity of the incident radiations, which is lost by employing a spectroscope.

From this it is evident that after exhausting the possibilities with the spectrobolometer the spectral transmission screen method becomes a valuable adjunct in extending the spectral radiation intensity investigations to stars which are too faint to measure with the spectrobolometer.

Furthermore, after exhausting the possibilities with the spectral transmission screen method, there still remains the photographic plate for determining the spectral energy distribution of the very faint blue and yellow stars, which, as first demonstrated by meas- 
urements through the water cell on bright stars of the same spectral class, have practically all their radiations of wave lengths situated in that part of the spectrum to which the photographic plate is sensitive.

It may be added that if this fact had been known to astronomers, instead of plotting the densities of the photographs of stellar spectra, they could have determined the spectral energy distribution of blue and yellow stars photographically long ago by simply calibrating the spectral sensitivity of their plates in terms of the spectral energy distribution of some standard source.

\section{PLANETARY RADIATION DEFINED.}

By planetary radiation is meant the emission of thermal radiation from a planet as a result of warming of its surface by exposure to solar radiation, including the heat that may be radiated by virtue of a possible high internal temperature of the planet itself. The temperature of the surface due to absorbed solar radiation and due to internal heat, if such exists, at most is probably not much higher than several hundred degrees centigrade, and hence the radiated energy will be predominately of long wave lengths -7 to $\mathrm{x} 2 \mu(\mu=0.00 \mathrm{Imm})$. Hence, by means of a cell of water $\mathrm{r} \mathrm{cm}$ in thickness (which has the property of absorbing radiation of wave lengths greater than $\mathrm{I} .5 \mu$ ) interposed in the path of the total radiation emanating from the planet, this long wave length radiation can be separated from the reflected solar radiation, and in this manner a measurement obtained of the planetary energy radiated. If there is planetary radiation, then the water cell transmission of the planet will be less than that of the direct solar radiation.

It is to be noted that the water cell can not separate the radiation due to internal heat (if such is present) from the energy reradiated as a result of warming of the surface by solar radiation. If the planet is subject to eclipse, as for example our moon, then it is possible to determine whether the unilluminated surface is warm and emits heat radiation.

While the surrounding atmosphere may not become warmed sufficiently to emit long wave length thermal radiation, it is, nevertheless, desirable to supplement the radiometric measurements with other information as to the density and other properties of the planet's atmosphere, in order to decide fully the proportions of the reradiated energy emanating from the surface of the planet and from its surrounding atmosphere. 
For instance, the radiometric measurements show practically the same water cell transmission for the radiations emanating from Jupiter as for the radiations coming directly from the sun. From astronomical observations it is known that the atmosphere of Jupiter is extensive and probably very dense as compared with that of the earth. Hence, not only is it to be concluded that the energy radiated from the interior of Jupiter is completely trapped in the lower levels of the atmosphere but also that there is no appreciable emission of long wave length thermal radiation from its outer atmosphere as the result of warming by solar radiation or by internal heat.

The present contribution to the subject of planetary radiation may therefore, perhaps, prove useful in elucidating the question whether the earth's outer atmosphere radiates appreciable energy into space or whether the outgoing raaiation is principally the so-called nocturnal radiation emanating from the earth's surface.

\section{APPARATUS AND PROCEDURE.}

The apparatus used in this work consisted of the 40-inch reflector (focal length 220 inches) belonging to the Lowell Observatory (altitude 7,250 feet), to which was attached a spectral radiometer consisting of transmission screens and a vacuum thermocouple of low-heat capacity and hence having a quick action. ${ }^{1}$

\section{DESCRIPTION OF THE VACUUM THERMOCOUPLES USED IN THE PRESENT WORK.}

The vacuum containers for the thermocouples were of the same general design used in the previous work. Four containers were taken to the observatory, a distance of 2,500 miles, without breakage.

The new thermocouples used in the present investigation were made of pure bismuth ${ }^{2}$ wire which was very strong and pliable.

The thermocouple receivers were made small, with the view of obtaining measurements on the bright and dark regions on Mars and Jupiter.

CONTAINER No. 7 remained the same as used in the measurements of 1914, except that about three years ago a new quartz

\footnotetext{
1 This method of determining the spectral energy distribution of stars was worked out early in rgrg. Since then the device has been given a thorough trial (at the Lowell Observatory in I92I) and found to fulfill all the claims made for it (see B. S. Sci. Papers No. 438, 1922.) By means of these transmission screens it was possible to obtain for the first time an insight into the radiation intensities in the complete spectrum of a star.

${ }^{2}$ From Adam Hilger (Ltd.), 75 A Camden Road, London, England.
} 
tube containing new metallic calcium was provided. This container was opened and reevacuated with a pump a year ago, since which time its vacuum has been maintained by means of the metallic calcium.

CONTAINER No. II was No. 8 used in I $92 \mathrm{I}$, but with new thermocouples of pure bismuth wire $0.025 \mathrm{~mm}$ in diameter and platinum-rhodium wire ${ }^{3} 0.020 \mathrm{~mm}$ in diameter.

The bismuth wire was $3 \mathrm{~mm}$ long, kept straight in order to prevent radiation from falling on both receivers when the planetary image was focused on one of them. The resistance of thermocouple No. I was $7.7 \mathrm{ohms}$, the diameter of the receivers being $0.28 \mathrm{~mm}$. The resistance of thermocouple No. 2 was $5.5 \mathrm{ohms}$, the receivers being 0.23 and $0.27 \mathrm{~mm}$, respectively. The receivers were small globules of tin, attached to the $\mathrm{Pt}-\mathrm{Rh}$ wire and pressed flat between glass plates as described in previous publications. These receivers were not so large in diameter as those used a year ago and attained temperature equilibrium in 2 to 3 seconds (instead of 8 to ro seconds) which was the time of swing of the galvanometer needle.

CONTAINER No. 12 was the old mounting, No. 9, used in $192 \mathrm{I}$ but with new thermocouples of $0.025 \mathrm{~mm}$ bismuth wire and of $0.020 \mathrm{~mm} \mathrm{Pt}-\mathrm{Rh}$ alloy wire. The bismuth wire (length 2.5 to $3 \mathrm{~mm}$ ) was bent $U$-shaped in order to bring the receivers close together, so that the star image could be quickly changed from one receiver to the other receiver. The resistances of thermocouples Nos. I and 2 were 4.7 and 4.4 ohms, respectively; the diameters of the receivers (of tin pressed flat) were 0.31 and $0.32 \mathrm{~mm}$, respectively.

CONTAINER No. Io remained as used in I92I. In containers Nos. Io and 12 the fluorite windows were attached by means of Boltwood's ${ }^{4}$ low vapor pressure cement. This cement has a low melting point which enables one to attach the fluorite window without cracking it. The vacuum in these two containers remained unusually constant, so that for weeks at a time it would have been unnecessary to heat the calcium.

In the previous paper ${ }^{5}$ it was shown that a thermocouple of tellurium is twice as sensitive as that of bismuth. This is to be expected in view of the fact that its thermal emf is twice that of bismuth. It may therefore be used for stellar radiometry

\footnotetext{
${ }^{3}$ From Baker \& Co., Newark, N. J.

1 From Prof. B. B. Boltwood, Yale University, New Haven, Conn.

${ }^{5}$ B. S. Sci. Papers, No. 438 ; 1922.
} 
provided it can be made of sufficiently small size in order to reduce its heat capacity and hence its lag in attaining a maximum temperature. The thermocouples of tellurium wire $(0.13 \mathrm{~mm}$ in diameter) tested required six to eight seconds to attain a maximum galvanometer deflection, which was entirely too prolonged for the purpose of the present work. The thermocouples used in this present research were practically instantaneous in their action, so that, as already stated, a galvanometer reading was obtained in two to three seconds which was the time of single swing of the galvanometer needle.

The radiation sensitivity of the thermocouples of pure bismuth wire used in 1922 was practically the same as that of the alloys used in the stellar measurements of $192 \mathrm{I}$. This is interesting in showing that, aside from a reduction in heat capacity and hence an increase in speed and accuracy of observation, there has been no great gain in radiation sensitivity by increasing the thermoelectric power or by reducing the size of the wire.

For measuring the direct solar radiation a special thermopile (in air) was used. It consisted of two elements of No. 38 constantan and No. 40 copper wire connected in series, with tin receivers I. 5 by $2.2 \mathrm{~mm}$ mounted in a brass box with an opening $8 \mathrm{~mm}$ in diameter covered with a fluorite window. The cold junctions were inside the brass box and shielded from the incident parallel light. This brass box was the exact size of the glass container for the stellar thermocouples, and it was mounted in the holder shown in Figure 4 of Bureau of Standard Scientific Papers, No. 438.

In view of the limited time available and also the preliminary nature of the planetary radiation measurements, a complete analysis could not be undertaken of the spectral components of the radiation emanating from the different planets. It was therefore necessary to choose between the water cell and the quartz plate for measuring the planetary radiation.

As shown on a subsequent page (Table 4) the spectral component radiation of wave lengths greater than $4 \mu$ is only about I per cent of the total incident solar radiation.

Hence, if a transmission screen of quartz is used, one would expect to find but a small amount of solar radiation mixed with the planetary radiation, unless there is strong selective reflection.

On the other hand, if there is planetary radiation of wave length shorter than $4 \mu$ it is missed in the transmission measurements made with the quartz screen. For, while the low temperature (planetary) radiation from solids is predominately of long 
wave lengths ( 6 to I $2 \mu$ ), the radiation emitted, of wave lengths 3 to $4 \mu$, are of measurable intensity. Similarly, the emission bands, at 3 to $4.2 \mu$, of water vapor and carbon dixoxide, even when heated to less than $100^{\circ} \mathrm{C}$., are also of measurable intensity. This is of importance in view of the question whether some of the planets are still hot.

Hence, if a water cell is used, one is certain of obtaining all the planetary radiation. The proportionate part of solar radiation will, of course, be greater than when using the quartz screen, but there is nothing to indicate that this is disadvantageous; for it does not appear that the atmospheres of the planets exert a selective reflection. It has been found that, as a general rule, the bands of selective reflection are not found in the short wave length infra-red region of the spectrum but occur at wave lengths greater than $6 \mu$. If the atmospheres of the planets modified the composition of the reflected solar radiation, and hence greatly vitiated the measurements of the planetary radiation, then one would expect to find this to occur in the case of the planets having the greatest atmospheres. As will be shown presently, the greatest amount of planetary radiation ( 7 to I $2 \mu$ ) comes from the planets having the smallest, least dense atmospheres.

The planetary radiation emanating from the moon, as observed through the water cell, is in substantial agreement with the measurements made years ago by Very, who used as a screen a plate of glass which, like quartz, is opaque to radiations of wave lengths greater than $4 \mu$.

For the present investigation the water cell was therefore adopted to obtain a uniform comparison of the measurements of the (planetary) radiation from the various planets.

\section{RADIOMETRIC MEASUREMENTS.}

Under this caption are given some of the experimental details relevant to obtaining a clear understanding of the scope and the reliability of the data obtained. By comparison of the water-cell transmissions of the radiations emanating directly from the sun with similar measurements of the radiations emanating from the planets a measure is obtained of the radiation emitted directly by the planet as a result of warming of its surface and atmosphere and as a result of a high internal temperature, if such a condition obtains.

$15525^{\circ}-23-2$ 


\section{THE SUN.}

A crucial part of this research consisted in obtaining an exact measurement of the water-cell transmission of the direct solar radiation for comparison with that of the planetary radiation. For this purpose the great reflecting mirror and the end of the telescope tube were covered, and the telescope was sighted upon the sun. Parallel light entering a small 6-inch ( $15 \mathrm{~cm}$ ) hole in the cover of the telescope tube fell upon a small $(5 \mathrm{~cm})$ plane silvered mirror placed in the axis of the tube and from thence reflected upon the diagonal mirror to the thermopile. In this manner a measurement was obtained of the solar radiation after reflection from two silvered surfaces just as obtained in the stellar and planetary radiation measurements. The plane mirror was used because of the high intensity of the solar rays. Even then it was necessary to insert 3,000 ohms into the galvanometer circuit in order to keep the galvanometer reading on the scale.

The observations consisted in noting the galvanometer reading when the end of the telescope tube was entirely covered. Solar radiation was then admitted upon the thermopile and a series of readings made with and without the intervening water cell. Readings were made also with the other transmission screens in order to obtain data given in the appendix. The day selected for observations was perfectly cloudless, and the galvanometer deflection remained steady to $0.5 \mathrm{~mm}$. This was a source of marvel to one who is accustomed to sea-level measurements with continuous galvanometer scale fluctuations caused by (visually) almost imperceptible clouds of water vapor.

TABLE 1.-Transmission of Planetary Radiation Through a Cell of Water $1 \mathrm{~cm}$ in Thickness; also the Percentage of Planetary Radiation Emitted.

\begin{tabular}{|c|c|c|c|c|c|c|}
\hline \multirow[b]{2}{*}{ Object. } & \multirow[b]{2}{*}{ Date. } & \multicolumn{4}{|c|}{ Percentage transmission. } & \multirow{2}{*}{$\begin{array}{l}\text { Plane- } \\
\text { tary radi- } \\
\text { atlon in } \\
\text { per cent } \\
\text { of the } \\
\text { total. }\end{array}$} \\
\hline & & $\begin{array}{c}\text { Sets of } \\
\text { measure- } \\
\text { ments. }\end{array}$ & $\begin{array}{c}\text { Deviation } \\
\text { from } \\
\text { mean. }\end{array}$ & $\begin{array}{l}\text { Mean } \\
\text { value, } \\
1922 .\end{array}$ & $\begin{array}{c}\text { Mean } \\
\text { value, } \\
\text { 1914. }\end{array}$ & \\
\hline & 1922 & & & & & \\
\hline 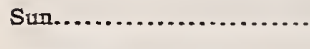 & Jinne $17-11.30$ a. $\mathrm{m} . .$. & $\begin{array}{l}5 \\
4\end{array}$ & $\begin{array}{r}1.2 \\
.5\end{array}$ & $\begin{array}{l}69.3 \\
69.8\end{array}$ & $\cdots$ & (n...... \\
\hline 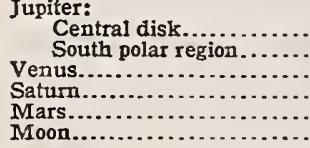 & $\begin{array}{l}\text { June } 14-10.15 \text { p. m.... } \\
10.20 \text { p. m.... } \\
\text { June } 15-8.00 \text { p. m..... } \\
\text { June } 14-9.00 \text { p. m..... } \\
\text { June } 15 \text { and } 18 . . . . . .\end{array}$ & $\begin{array}{l}2 \\
2 \\
2 \\
3\end{array}$ & $\begin{array}{l}1.4 \\
3.0 \\
2.3 \\
1.1 \\
6.0\end{array}$ & $\begin{array}{l}69.7 \\
66.8 \\
66.3 \\
60.0 \\
50.3\end{array}$ & $\begin{array}{r}65.6 \\
65.8 \\
59.0 \\
55.0 \\
14.7\end{array}$ & $\begin{array}{r}5 \\
15 \\
30 \\
80\end{array}$ \\
\hline
\end{tabular}


The transmission measurements are given in Table $\mathrm{I}$. In column 3 a "set of measurements" consisted in observing (I) the "zero reading" of the galvanometer with the end of the telescope tube covered, then (2) a series of galvanometer readings on exposure of the thermopile to the sun, but without the water cell, then (3) a series with the water cell interposed, followed by (4) another series without the water cell, and finally (5) another series of galvanometer zero readings.

The water-cell transmission is about 70 per cent, which is in agreement with measurements at sea level (Washington) which gave a transmission of 76 per cent (B. S. Tech. Papers No. 93, third edition, p. 25) for this same cell. For the latter measurement no reflecting mirrors were used, and hence the higher percentage transmission may be ascribed to depletion of infra-red radiation by atmospheric water vapor.

\section{VENUS.}

The water-cell transmissions on Venus were made with thermocouple No. 2 in container No. II. The method of observation consisted in exposing both of the thermocouple receivers to the sky, then moving one of them upon the planetary image by turning the slow-motion declination screw. Similar measurements were made also in the reverse order. The ratio of the galvanometer deflections, with and without the water cell, gives the transmission data desired. These data are given in Table $\mathrm{I}$, the transmission being about 66 per cent.

\section{MARS.}

The transmission measurements on Mars were obtained by means of two thermocouples differing widely in construction, as described on a preceding page.

In order to obtain the galvanometer deflections quickly when using thermocouple No. 2 in container No. II, the procedure was to tilt the telescope tube a slight amount so that the image of Mars was "on" or "off" the thermocouple receiver (that is, both receivers were exposed to the clear sky). The data are given in Table 2, in which the second column gives the "number of sets of galvanometer readings," the first set being made without the water cell interposed and the second set being obtained with the water cell in the path of the incident radiation. This was sometimes followed by a third set of readings without the water cell. The ratio of the average values of two such sets of observations 
is the transmission recorded in column 6 . Columns 3,5 , and 7 give the maximum deviation of a single galvanometer deflection from the mean value of a single set of observations. Column 9 gives the mean value of the direct deflection. Since the mean value of the set of observations is the result of ro to ${ }_{5} 5$ single galvanometer deflections, a large variation of a single reading has no serious effect upon the results.

TABLE 2.- Mars; Transmission of Planetary Radiation Through $1 \mathrm{~cm}$ of Water, Using Vacuum Mounting No. 11, Thermocouple No. 2.

\begin{tabular}{|c|c|c|c|c|c|c|c|c|}
\hline \multirow[b]{3}{*}{$\begin{array}{c}\text { Date-p. m., } \\
\text { June } 15,1922, \\
\text { IV. S. T. }\end{array}$} & \multirow[b]{3}{*}{$\begin{array}{c}\text { Sets of } \\
\text { galva- } \\
\text { nometer } \\
\text { readings. }\end{array}$} & \multicolumn{6}{|c|}{ Percentage transmission. } & \multirow[b]{3}{*}{$\begin{array}{c}\text { Observed } \\
\text { galva- } \\
\text { nometer } \\
\text { deflection. }\end{array}$} \\
\hline & & \multicolumn{2}{|c|}{ South polar setting. } & \multicolumn{2}{|c|}{ Equatorial region. } & \multicolumn{2}{|c|}{ North polar setting. } & \\
\hline & & \begin{tabular}{|c|} 
Maximum \\
deviation \\
of a \\
single \\
galva- \\
nometer \\
deflection \\
from \\
mean.
\end{tabular} & $\begin{array}{c}\text { Mean } \\
\text { value } \\
\text { of } \\
\text { trans- } \\
\text { mission. }\end{array}$ & $\begin{array}{l}\text { Maximum } \\
\text { deviation } \\
\text { of a } \\
\text { single } \\
\text { galva- } \\
\text { nometer } \\
\text { deflection } \\
\text { from } \\
\text { mean. }\end{array}$ & $\begin{array}{c}\text { Mean } \\
\text { value } \\
\text { of } \\
\text { trans- } \\
\text { mission. }\end{array}$ & $\begin{array}{c}\text { Maximum } \\
\text { deviation } \\
\text { of a } \\
\text { single } \\
\text { galva- } \\
\text { nometer } \\
\text { deflection } \\
\text { from } \\
\text { mean. }\end{array}$ & $\begin{array}{c}\text { Mean } \\
\text { value } \\
\text { of } \\
\text { trans- } \\
\text { mission. }\end{array}$ & \\
\hline $\begin{array}{l}10.58 \text { to } 11.05 \ldots \ldots \\
11.07 \text { to } 11.10 \ldots \ldots \\
11.12 \text { to } 11.13 \ldots \ldots \\
11.16 \text { to } 11.18 \ldots \ldots \\
11.22 \text { to } 11.24 \ldots \ldots \\
11.25 \text { to } 11.28 \ldots \ldots \\
11.44 \text { to } 11.48 \ldots \ldots \\
11.55 \text { to } 11.58 \ldots \ldots \\
12.05 \text { to } 12.12 \ldots \ldots \\
12.20 \text { to } 12.27 \ldots \ldots\end{array}$ & $\begin{array}{l}2 \\
2 \\
2 \\
2 \\
2 \\
2 \\
2 \\
2 \\
3 \\
3\end{array}$ & 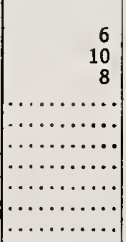 & 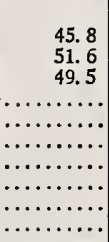 & 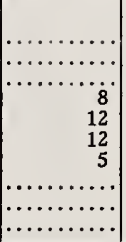 & 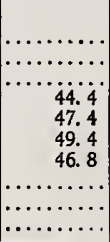 & 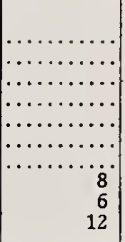 & 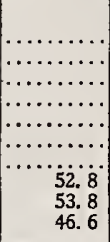 & \begin{tabular}{r}
\multicolumn{1}{|c}{ cm } \\
4.8 \\
3.4 \\
$\ldots \ldots . .4$ \\
5.4 \\
5.5 \\
5.2 \\
6.1 \\
3.8 \\
3.3 \\
3.6
\end{tabular} \\
\hline Mean value & & $\ldots \ldots \ldots$ & 48.9 & $\cdots$ & 47.0 & . & 51.1 & \\
\hline
\end{tabular}

i. Mean value of all $=49$ per cent.

As already described, the bismuth wire of the thermocouples in container No. 12 were bent into a $U$ shape, the receivers being separated about $\mathrm{I} \mathrm{mm}$. The diameters of the receivers were about 0.4 of the diameter of the planetary disk.

The method of observation consisted in exposing alternately the two junctures of the thermocouple (No. I was used), thus doubling the galvanometer deflection. The procedure was to expose the left thermocouple receiver to the planetary image and record 5 to 6 galvanometer scale readings. The image was then focused on the right-hand thermocouple receiver, and a similar series of galvanometer scale readings were recorded. The difference of the average of the "left" and the "right" scale readings constituted a "set of galvanometer readings." Several such sets were then obtained alternately with and without the 
water cell interposed. The number of sets of readings are given in column 2 of Table 3 .

TABLE 3.-Mars; Transmission of Planetary Radiation Through $1 \mathrm{~cm}$ of Water, Using Vacuum Mounting No. 12, Thermocouple No. 1.

\begin{tabular}{|c|c|c|c|c|c|c|c|c|}
\hline \multirow[b]{3}{*}{$\begin{array}{c}\text { Date-p. m., } \\
\text { June } 18,1922, \\
\text { M. S. T. }\end{array}$} & \multirow[b]{3}{*}{$\begin{array}{l}\text { Sets of } \\
\text { galva- } \\
\text { nometer } \\
\text { readings. }\end{array}$} & \multicolumn{6}{|c|}{ Percentage transmission. } & \multirow[b]{3}{*}{$\begin{array}{c}\text { Observed } \\
\text { galva- } \\
\text { nometer } \\
\text { deflec- } \\
\text { tion. }\end{array}$} \\
\hline & & \multicolumn{2}{|c|}{ South polar setting. } & \multicolumn{2}{|c|}{ Equatorial region. } & \multicolumn{2}{|c|}{ North polar setting. } & \\
\hline & & $\begin{array}{c}\text { Marimum } \\
\text { deviation } \\
\text { of average } \\
\text { galva- } \\
\text { nometer } \\
\text { deflection } \\
\text { from mean } \\
\text { of several } \\
\text { sets. }\end{array}$ & $\begin{array}{c}\text { Mean } \\
\text { value of } \\
\text { trans- } \\
\text { mission. }\end{array}$ & $\begin{array}{c}\text { Maximum } \\
\text { deviation } \\
\text { of average } \\
\text { galva- } \\
\text { nometer } \\
\text { deflection } \\
\text { from mean } \\
\text { of several } \\
\text { sets. }\end{array}$ & $\begin{array}{l}\text { Mean } \\
\text { value of } \\
\text { trans- } \\
\text { mission. }\end{array}$ & $\begin{array}{c}\text { Marimum } \\
\text { deviation } \\
\text { of average } \\
\text { galva- } \\
\text { nometer } \\
\text { deflection } \\
\text { from mean } \\
\text { of several } \\
\text { sets. }\end{array}$ & $\begin{array}{c}\text { Mean } \\
\text { value of } \\
\text { trans- } \\
\text { mission. }\end{array}$ & \\
\hline $\begin{array}{l}10.25 \ldots \ldots \ldots \\
10.30 \ldots \ldots \\
10.40 \ldots \ldots \\
10.50 \ldots \ldots \\
11.10 \ldots \ldots \\
11.15 \ldots \ldots \\
11.25 \text { to } 11.45 \ldots \ldots\end{array}$ & \begin{tabular}{r|}
6 \\
6 \\
12 \\
10 \\
5 \\
7 \\
12
\end{tabular} & 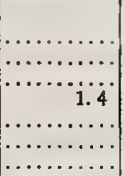 & 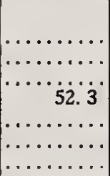 & 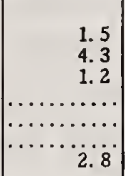 & 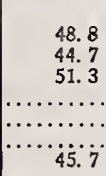 & 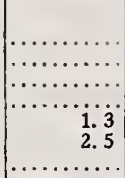 & 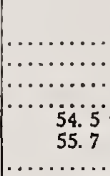 & 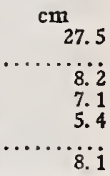 \\
\hline $\begin{array}{l}\text { Mean value, } \\
\text { June } 18 \ldots . . \\
\text { Mean value, } \\
\text { June } 15 \ldots .\end{array}$ & & & $\begin{array}{l}52.3 \\
48.9\end{array}$ & & $\begin{array}{l}47.6 \\
47.0\end{array}$ & & $\begin{array}{l}55.1 \\
51.1\end{array}$ & \\
\hline $\begin{array}{l}\text { Mean value, } \\
\text { June } 15 \text { and } \\
18 \ldots \ldots \ldots\end{array}$ & & & 50.6 & & 47.3 & & 53.1 & $\cdots$ \\
\hline
\end{tabular}

1 Mean value of all $=50.3$ per cent.

Columns 3, 5, and 7 of Table 3 differ from similar data in Table 2 in that the maximum deviation is not that of a single reading from the mean of a series of readings, but is the percentage deviation of the mean of a single set of galvanometer readings from the mean of the three to six sets taken with (or without) the water cell intervening. The various sets of readings being average values, the percentage deviation from the mean of several sets is smaller than that given in Table 2 for single readings. The deviations are smaller also for the reason that there was less unsteadiness in the galvanometer reading when the thermocouples were exposed alternately to the planetary image than when a single receiver was exposed alternately to the sky and the planet. In Table 3 all the data following the first two series of transmissions were obtained with a (low and) constant galvanometer sensitivity. Hence the galvanometer deflections recorded in column 9 are proportional to the radiation emanating from Mars, and show that the intensity of the radiation emanating from the Southern Hemisphere, the Equator, and the Northern Hemisphere on June I 8 was, respec$15525^{\circ}-23-3$ 
tively, $7.1,8.2$, and $5.4 \mathrm{~cm}$. In this connection it is interesting to note that while making observations on the equatorial region meteorological conditions continued uniform for an hour, so that the observations at the beginning and the end are in agreement within I per cent.

The water-cell transmissions of the radiations from the southern (50.6 per cent) and northern (53.I per cent) hemispheres of Mars should be and are higher than that of the radiations emanating from the equatorial ( 47.3 per cent) region, owing to a smaller degree of heating of the polar regions (because in these regions the solar radiation traverses a greater air mass and is incident at greater obliquity upon the Martian surface) and also owing to the depletion of the outgoing reflected and reradiated energy by the same air mass. At the time of the observations the sun was only about $2^{\circ}$ north of the planet's equator, so that the insolation of each hemisphere was practically the same. Moreover, the declination of the earth on Mars was only about $7^{\circ}$, which simplified the comparison. Hence, from the positions of the earth and the sun as viewed from Mars, one would expect to obtain closely the same transmissions, provided these two regions become equally warmed, and provided there are no clouds to intercept the reradiated energy. The observations obtained with two thermocouples differing widely in construction and on different dates are consistent in showing a lower water-cell transmission (a higher reemission) of thermal radiation from the southern hemisphere than from the northern hemisphere, which is visually the brighter of the two. From this one might hastily conclude that the dark southern hemisphere emits more of the long wave-length radiation than does the north polar region. This is an instance where the explanation of the radiometric measurements appears to require supplementary observations. According to the photographic and visual observations of $\mathrm{E}$. C. Slipher, which were in progress at the time of making the radiometric measurements, the north polar and temperate regions exhibited cloudiness which would tend to trap the reradiated long wave-length emission, thus raising the values of the water-cell transmissions. Hence, the cause of the higher value of the water-cell transmission of the radiation from the (brighter) northern hemisphere is to be ascribed partly to the presence of clouds which trap the planetary radiation, and one can not decide whether the dark areas of the southern hemisphere are bare ground which have become warmed or whether 
they consist of growing vegetation which, according to the writer's temperature measurements ${ }^{6}$ of growing terrestrial plants, does not rise in temperature much above that of the surrounding air.

\section{JUPITER.}

The water-cell transmissions of the radiation from Jupiter were determined with thermocouple No. 2 in the vacuum container No. II. The receiver intercepted about one-fourth of the image of the disk of the planet. The measurements were made by exposing one receiver alternately to the planetary disk and then (when conditions were steady) to the sky, thus obtaining a set of galvanometer deflections. Several such sets of observations were obtained with and without the water cell interposed. The data are given in Table $\mathbf{I}$, from which it may be noticed that the value of the transmission is practically the same (70 per cent) as that of the direct solar radiation, also that the observations are in agreement with those obtained in 1914 at Mount Hamilton, which is at a considerably lower altitude. From this it appears that Jupiter's atmosphere does not radiate appreciable infra-red energy as the result of warming by solar rays and by internal heat, and that the atmosphere is sufficiently thick and opaque to trap all the energy radiated as the result of heating of its interior by solar radiation, or that may be emitted as a result of a high internal temperature, if such a condition exists.

\section{SATURN.}

The water-cell transmission measurements on the center of the ball of Saturn were made with thermocouple No. 2 in vacuum mounting No. II. The diameter of the receiver was about onehalf of the disk. The rings at this time were too narrow and of too low intensity to measure radiometrically. The procedure was to expose one thermocouple receiver to the planetary disk and, when the galvanometer was steady, expose both receivers to the sky by slightly tilting the telescope tube.

The transmission data are given in Table $I$. The average value (6o per cent) of the water-cell transmission is appreciably lower than that of the direct solar radiation, and it is in agreement with the observations of I9I4, showing a considerable amount of infrared radiation not present in the direct solar radiation.

${ }^{6}$ Annual Report of the Director of the Bureau of Standards, I916. On p. 93 the report of the section on radiometry shows that the temperature of growing leaves in direct sunlight may be 5 to $6^{\circ} \mathrm{C}$. higher than that of the surrounding air, while the unilluminated leaf, owing to evaporation of moisture, is at a lower temperature than the air. 
6. THE MOON.

No observations of the water-cell transmission of the radiation from the moon were obtained this year for an air mass comparable with that through which the planetary measurements were obtained. Since the present (as well as the 192I) radiation measurements on all of the other objects are in agreement with the observations of 1914 , it is to be assumed that the water-cell transmission of the lunar radiation is of the order of 15 per cent (see Table I) as observed in r 914.

In connection with the planetary measurements this forms an interesting sequence of water-cell transmissions which decrease (that is, the percentage of planetary radiation increases, Table I) with decrease in thickness and density of the planetary atmospheres Jupiter (69), Venus (66), Saturn (60), Mars (50), and the moon (15). The percentage difference between the watercell transmission of the direct solar radiation and that of the radiation emanating from the planet is a measure of the planetary radiation (see Table I), and is as follows: Jupiter (o), Venus (5), Saturn (15), Mars (30), and the moon (80).

\section{DISCUSSION OF DATA.}

In the foregoing pages data are presented showing that the order of the intensity of the planetary radiation, as interpreted from measurements of the total radiation emanating from the planet which is transmitted through a cell of water, is as follows: Jupiter (the least), Venus, Saturn, Mars, and the moon (the greatest). This planetary radiation may consist of (I) the energy reradiated as the result of heating of the planet (including both the surface and the atmosphere, if the latter contributes radiation) by solar rays, (2) the energy which may be radiated owing to a high internal planetary temperature, if such a condition obtains, and (3) solar radiation which may be selectively reflected from the planet (including surface and atmosphere). In order to estimate the part contributed by each of these sources of long wave length infra-red radiation, it is necessary to consider other information on the planets.

\section{PLANETARY TEMPERATURES.}

In his theoretical investigation of the radiation from the solar system, assuming that the planets are similar to the earth, Poynting $^{7}$ calculated the following temperatures: Mercury $196^{\circ} \mathrm{C}$.,

7 Poynting, Phil. Trans. Roy. Soc., 202 A 525, 1903; Jahrbuch der Radiovaktivität w. Elektronik, 2. 42,1905 . 
Venus $69^{\circ} \mathrm{C}$., earth $17^{\circ} \mathrm{C}$., Mars $-38^{\circ} \mathrm{C}$. He omitted Jupiter and Saturn in view of the probability that they radiated heat of their orn in considerable proportion. Using more recent data on the solar constant would not affect these calculations in a marked degree. Calculations of this type ${ }^{s}$ indicate a lunar temperature of $82^{\circ} \mathrm{C}$. for the full moon.

Probably the most convincing experimental observations of the range of temperature of the moon are those of Langley and Very ${ }^{\circ}$ and later those of Very. ${ }^{10}$

These measurements indicate inferred effective lunar temperatures ranging from 45 to over $100^{\circ} \mathrm{C}$.

Lowell's $\mathrm{s}^{11}$ calculations of the surface temperature of Mars gives values much higher than those obtained by Poynting and others; and they are in agreement with what one would expect from the radiation measurements recorded in the present paper. His calculations, taking into account factors previously neglected and based on the heat retained, give a mean temperature of $48^{\circ} \mathrm{F}$. $\left(9^{\circ} \mathrm{C}\right.$.) for the surface of Mars, while another calculation gives a temperature of $22^{\circ} \mathrm{C}$. He points out that owing to cloudiness only 60 per cent of the incident solar radiation is effective in warming the earth, while 99 per cent is effective in warming the surface of Mars. Other meteorological data of interest are that, on Mars, water boils at $44^{\circ} \mathrm{C}$., that the amount of air per unit surface is I $77 \mathrm{~mm}$ (two-ninths the earth's), and that the density of the air at the surface is $63 \mathrm{~mm}$ (one-twelfth the earth's).

In a recent discussion of climatic conditions on Mars, inferred from phenomena generally observed on the planet, Pickering ${ }^{12}$ estimates the mean annual temperature at $+20^{\circ} \mathrm{F}$. as compared with the mean annual temperature of the earth of $+59^{\circ} \mathrm{F}$. $\left(15^{\circ} \mathrm{C}\right.$.). At night the Martian temperature is below $32^{\circ} \mathrm{F}$. $\left(0^{\circ} \mathrm{C}\right.$.), and at noon it is, perhaps, 60 to $70^{\circ} \mathrm{F}$. ( 15 to $20^{\circ} \mathrm{C}$.). These figures are arrived at from the appearance and dissappearance of snow and frost during the course of the Martian day, and from the fact that snow is never seen on the equator at Martian noon.

\section{SELECTIVE REFLECTION OF SOLAR RADIATION.}

Investigations of infra-red reflection spectra ${ }^{13}$ show that silicates, carbonate, and sulphates have the property of selective

\footnotetext{
${ }^{8}$ Coblentz, Investig. of Infra-red Spectra, Publ. No. 97, Carnegie Institute of Washington, p. I35; Ig08.

${ }^{9}$ Langley and Very, Nat. Acad. Science, 3 (I884) and 4 ; 1887.

${ }^{10}$ Very, Astrophys. J., 8, pp. I99 and 284, 1898; 24, p. 351, 1906.

11 Lowell, Phil. Mag. (6), 14, p. 16r; 1907.

12 Pickering, Popular Astronomy, 30, p. 4 10; 1922.

${ }^{13}$ Coblentz, Publications Nos. 65 and 97 , Carnegie Institute of Washington.
} 
reflection in the region of the spectrum extending from 6 to Io $\mu$, and the question arose as to the effect this would have upon the solar radiation reflected from a surface like the earth or moon, which is no doubt composed largely of silicates. In the region of selective reflection the radiations that would ordinarily be emitted as a result of warming of the surface by absorption of solar radiation are suppressed. In that paper no estimate could be obtained of the selectively reflected solar radiation of wave lengths 8 to $10 \mu$ which is superposed upon the directly emitted lunar radiation.

More recent consideration of the phenomenon does not alter the conclusion that such a selective reflection must exist if the pianetary surface contains silicates. However, from an estimate of the probable magnitude of the selective reflection and from the calculations of the temperature rise of the planets, it appears that for the purpose of the present paper the planetary radiation may be considered practically free from selectively reflected solar radiation.

\section{MARS.}

If the foregoing assumption is not made, then the great amount of infra-red radiation from Mars must be assumed to be the result of a high selective reflection instead of an appreciable temperature rise of the surface. On the other hand, the low density of the Martian atmosphere would permit cooling of the unilluminated surface, with the formation of snow and frost as observed. Hence, the evidence supports the view that the surface of Mars becomes appreciably heated by solar radiation with the consequent high emission of infra-red radiation as observed. This is in agreement with conclusions as to the radiation from the moon, the illuminated surface of which no doubt becomes highly heated, with the consequent high emission of infra-red rays, as observed.

Concerning the difference in the radiation from the northern and the southern hemispheres of Mars, it is of interest to record that when the observations were in progress the winter season was approaching in the northern hemisphere, when one would expect cloudiness and when on many previous oppositions it was observed that the poles were hidden in a mist. The radiometric measurements show a decidedly lower total radiation from the northern hemisphere in spite of the fact that it is the brighter visually and photographically. This is, of course, to be expected in view of the approaching winter season on the northern hemisphere, when the surface is cooling (hence a lower planetary 
radiation) and the outgoing planetary radiation is being trapped by increasing cloudiness. The abservations of Langley, Very, Julius, Boeddicker, etc., show that during an eclipse of the moon there is a sudden and very rapid fall in temperature and intensity of thermal radiation at the beginning of the eclipse and an equally rapid increase in infra-red radiation after its conclusion. From this and from our knowledge of terrestrial conditions it seems that there is probably no marked lag in the cooling (or warming) of the Martian surface with change in season.

The radiometric measurements show that about 30 per cent of the total radiation from Mars is planetary, as the result primarily of warming of the surface by solar radiation. Such a rise in temperature, as already mentioned, is in agreement with other meteorological data bearing on this subject. In fact, these measurements confirm other observational evidence that the Martian surface becomes appreciably warmed by solar radiation. It is an interesting speculation as to the weather conditions, cloudiness, etc., of a planet like Mars, which has a thin atmospheric envelope as compared with the moon, which is devoid of an atmosphere, or with Venus, which has a dense atmosphere.

\section{JUPITER.}

Spectrum photographs of Jupiter and Saturn are very similar. From this it would appear that their atmospheres are somewhat similar in composition. As already mentioned, the water-cell transmissions of the radiations emanating from Jupiter indicate that the outer atmospheric envelope does not become warmed sufficiently by solar or internal heat to cause it to emit an appreciable amount of infra-red rays, and that any radiation emanating from the interior is completely trapped by the outer layers of the atmosphere.

An explanation can be given to the observations that the outer atmosphere of Jupiter does not emit an appreciable amount of infra-red radiation. Only those constituents (for example, water vapor, ozone, and carbon dioxide) which have absorption bands in the region of 6 to I $2 \mu$ will become heated by absorption of the long wave length radiation. Other constituents (for example, oxygen, hydrogen, nitrogen, and helium) which are transparent to these radiations will become heated only by conduction, and the average temperature and emission of long wave length infrared radiation will be lower than would obtain if all the constituents were absorbing radiation. The infra-red radiation is dissipated 
in the great mass of atmospheric constituents which can not reemit them (at the low temperatures which prevail) and there is no appreciable emission of long wave length ( 7 to $12 \mu$ ) thermal radiation, as observed.

\section{SATURN.}

From I $_{2}$ to $\mathrm{x} 5$ per cent of the total radiation emanating from the ball of Saturn is long wave length, planetary radiation. Since the spectroscopic evidence indicates that the outer atmospheres of Jupiter and Saturn are qualitatively the same, it is to be inferred that the Saturnian atmosphere does not become heated (because of the greater solar distance it receives perhaps only one-fiftieth of the solar radiation incident upon Jupiter) and emit infra-red radiation, and that the observed planetary radiation which emanates from the interior of Saturn is not entirely trapped by its outer atmosphere because of its lower density and low absorptivity of long wave length infra-red radiations. In view of the relatively great density of the atmosphere of Saturn as compared with that of Mars, and in view of the high planetary radiation ( 5 per cent) of Saturn which (because of its greater solar distance) one would expect to be less if it is the result entirely of solar radiation, as compared with that of Mars (3o per cent), it is an interesting question whether any radiation is emitted by the ball of Saturn as a result of a possible high internal temperature.

\section{VENUS.}

The radiometric measurements on Venus are interesting in showing only a small planetary radiation. Owing to the nearness of Venus to the sun it is interesting to note that both planets have high visual albedos (Venus 0.59 , Jupiter 0.56 ) and are subject to great differences of intensity of solar radiation, (Jupiter : Venus :: I $: 57.5$, approximately, at date of observation) with small planetary radiation-Jupiter o per cent, Venus 5 per cent.

Theory would lead us to expect an atmosphere on Venus similar in constitution to that on our earth. But since the intensity of solar radiation incident upon Venus is almost two times that incident on the earth, there should be a greater heating of the surface and of the lower atmospheric layers if the solar energy is transmitted by its atmosphere proportionately on Venus as on the earth. As mentioned above, Poynting calculated a surface temperature of $69^{\circ} \mathrm{C}$. for Venus as compared with $17^{\circ} \mathrm{C}$. for the earth. From these considerations it is of interest to note that 
only 5 per cent of the planetary radiation either emanates from or escapes through the atmosphere of Venus. Similarly, on clear nights the outgoing terrestrial nocturnal radiation at sea level is only Io to I 2 per cent of the solar radiation intensity at the earth's surface, and in cloudy weather it is nil.

It is relevant to add that, although the superficial condition of the planets is constantly changing, there is a marked agreement in the radiometric observations of $\mathrm{IgI}_{4}$ and the present observations on Jupiter, Saturn, and Venus.

\section{THE MOON.}

As already stated, the water-cell transmission of the radiation from the moon is low ( 5 per cent), indicating a large temperature rise of the lunar surface due to heating by solar radiation. Furthermore, this superficial temperature is estimated at from 80 to more than $100^{\circ} \mathrm{C}$. after prolonged insolation. By comparison of the planetary radiation from the moon and from Mars it appears that the temperature rise of Mars is considerable-perhaps Io to $20^{\circ} \mathrm{C}$.

In conclusion it may be added that the unexpected observation of a considerable heating of the surface of Mars raises the question whether the calculations of planetary temperatures are in error or whether the total solar radiation intensity (the "solar constant") outside our atmosphere is higher than the present accepted value.

\section{SUMMARY.}

The present investigation was undertaken for the purpose of obtaining measurements of the thermal radiation emitted from a planet as a result of warming of its surface by exposure to solar radiation, including heat radiated by virtue of a possible high internal temperature of the planet itself, and also selectively reflected solar radiation of long wave lengths. It is shown that the latter is probably small and negligible in comparison with the radiation emitted as a result of heating by solar radiation.

By comparing the transmission of the direct solar radiation through a $\mathrm{I} \mathrm{cm}$ cell of water with the transmission of the radiation emanating from the planet a measurement is obtained of the intensity of the planetary radiation.

Radiometric measurements were made on Venus, Mars, Jupiter, Saturn, and the sun, and in cases where similar measurements had been made at Mount Hamilton, Calif., in I9I4, the data were found in good agreement. 
The radiometric measurements of the water-cell transmissions of the radiations from Jupiter and from the sun were practically the same, indicating (I) that the outer atmosphere of Jupiter does not become sufficiently heated to emit long wave length ( 7 to I $2 \mu$ ) radiation, and (2) that any long wave length radiation emanating from its interior is entirely trapped by the surrounding atmosphere.

The intensity of the planetary radiation increases with decrease in the density of the surrounding atmosphere, and (as interpreted from the water-cell transmissions) in percentage of the total radiation emitted is as follows: Jupiter (0), Venus (5), Saturn (15), Mars (30), and the moon (80).

The intensity of the planetary radiation from the northern hemisphere of Mars was found to be less than from the southern hemisphere. This is to be expected in view of the observed cloudiness over the northern hemisphere, which is approaching the winter season and hence is at a lower superficial temperature.

In the appendix measurements are given of the spectral energy distribution and the temperature of the sun as determined by means of a series of transmission screens placed in front of the stellar radiometer. The data obtained verify previous measurements indicating stellar temperatures ranging from $3,000^{\circ} \mathrm{K}$. for red (class-M) stars to $12,000^{\circ} \mathrm{K}$. for blue (class-B) stars.

\section{SUPPLEMENTAL DISCUSSION.}

The problem of the radiation from a planet and its surrounding atmosphere is exceedingly complex and it is manifestly impractical to enter into a discussion of the numerous subsidiary questions involved.

The observational work is preliminary and, in the meantime, it must suffice to amplify certain statements in the main part of this paper. For example, in defining planetary radiation, the writer had in mind terrestrial atmospheric absorption (of water vapor, $\mathrm{CO}_{2}$ and ozone) which is practically complete in the spectral regions from 4 to $7.5 \mu$ and for wave lengths greater than I4 $\mu$. Hence, even though a planet may be radiating all wave lengths extending from 3 to $100 \mu$, only those wave lengths extending from 7 to $14 \mu$ will be transmitted to the earth's surface. From this viewpoint, the statement (p. 537) that the planetary radiation is predominately of wave lengths extending from 7 to $12 \mu$ seems consistent. 
The limit set at I $2 \mu$ is owing to the fact that the fluorite window ( $2 \mathrm{~mm}$ in thickness) of the vacuum thermopile is opaque to radiation of wave lengths greater than I2.5 $\mu$. By using a rock-salt window, the planetary radiation (if any is emitted) of wave lengths extending from I 2 to I $4 \mu$ would be observable, and hence the transmission data might be relatively different from those given in Table $\mathrm{I}$.

Until the spectral energy curve of the planetary radiation can be observed, it will be quite impossible to conjecture as to what proportion of the planetary radiation is absorbed by the terrestrial atmosphere. Hence, the statement (p. 548) that the water-cell transmission is a measure of the planetary radiation, must remain indefinite, and the values assigned to the various planets are not comparable. For example, the value (80) given for the moon may represent practically all the planetary radiation emitted. On the other hand, the value (5) assigned to Venus may represent only Io per cent of the total planetary radiation, of all wave lengths, emitted; the remaining 90 per cent being of wave lengths which are absorbed by the earth's atmosphere.

It is impractical to enter into a discussion of the radiative equilibrium of the planets. It is generally assumed that the planetary temperature has reached a steady state. It is also generally conceded that all bodies above the absolute zero of temperature emit thermal radiation. The fact that practically no planetary radiation was observed from Venus means simply the absence of radiation of wave lengths from 7 to I2 $\mu$. But nothing is known of its emission of radiation of wave lengths 4 to $7 \mu$ and of wave lengths greater than I $5 \mu$ which is absorbed by our atmosphere.

Abbot (in his book on The Sun and in other papers) shows that but little of the nocturnal radiation from the earth's surface escapes into space, and that the earth's effective radiating layer may be regarded as situated in the atmosphere, consisting chiefly of layers of water vapor, at an elevation of several miles, and at an average temperature of about $-10^{\circ} \mathrm{C}$. It is generally supposed that Kirchoff's law of emission and absorption holds. Hence, at this low temperature the water vapor emission will be predominately of wave lengths greater than I4 $\mu$, with a less intense emission of radiation of wave lengths 4 to $7 \mu$. An observer, using the herein-described water cell apparatus on a planet similar to the earth, would therefore conclude that practi- 
cally all the planetary radiation (the nocturnal radiation of wave lengths 7 to $12 \mu$, emitted by the earth's surface) is trapped by the earth's atmosphere. Furthermore, he would not observe the radiation emitted by the water vapor of the earth's atmosphere, because it is absorbed by the water vapor in the atmosphere of the planet he used as an observing station.

It is not unreasonable to suppose that there is a similar effective radiating layer in the atmosphere of Venus, the temperature of which will no doubt be higher than that assigned to the earth. The nocturnal radiation from the surface of Venus (like that of the earth) will be small, as observed. The radiation emitted by the water vapor in the atmosphere of Venus will be absorbed by the earth's atmosphere and the planetary radiation is low, as observed. No doubt there are other explanations to account for the absence of planetary radiation from Venus, but this one seems to account for the unexpected observation of practically no radiation of wave lengths 7 to $12 \mu$.

If the temperature of the effective radiating layer of the earth's atmosphere is low $\left(-10^{\circ} \mathrm{C}\right.$.) as estimated by Abbot, it may be assumed that, if Jupiter has a similar effective radiating layer, its temperature will be still lower, owing to the greater solar distance. Hence, the atmospheric radiation will be mainly of wave lengths greater than $15 \mu$ which are absorbed by the earth's atmosphere. The statement (on p. 55x) that the radiation emanating from the interior of Jupiter is completely trapped refers, of course, to the observable spectral region of 7 to i $2 \mu$.

From these considerations it does not appear inconsistent with the theory of radiative equilibrium and planetary temperatures to find practically no emission of thermal radiation of wave lengths 7 to $12 \mu$ from the planets which have thick, dense atmospheres. It means simply that, owing to terrestrial atmospheric absorption, we can not observe the radiation emitted by these planets.

In conclusion, it is relevant to emphasize that this paper presents the results of a search for a means of investigating the radiation (particularly from the interior) of a planet. These results show that, for planets having dense atmospheres, the secrets within remain hidden. On the other hand, in a planet like Mars a way has been shown for studying the radiation from different parts of the interior. The observation of accurate quantitative data must await the future. 


\section{APPENDIX.-CONCERNING STELLAR TEMPERATURES.}

In a previous paper ${ }^{14}$ data are given on the spectral energy distribution and the temperature of 16 stars as determined by means of a series of transmission screens placed in front of a vacuum thermocouple, as described and illustrated in a foregoing part of the present paper.

Not being equipped at that time for making radiometric measurements on the sun, the effective temperature of which is known with some degree of accuracy and hence could be used as a standard, an estimate of the effective temperature of a star was obtained by two methods. One method consisted in making all corrections to the observations excepting those for atmospheric absorption and comparing them with the calculated values, using a solar type star ( $\alpha$ Aurigæ, class Go, spectroscopic binary) as a standard. This seemed permissible in view of the fact that the observed temperature $\left(6,000^{\circ} \mathrm{K}\right.$.) of $\alpha$ Aurigæ was found to be in close agreement with that assigned to the sun. The results of the present investigation show that this procedure was satisfactory.

As mentioned in Section II, for the present investigation a special thermocouple was provided for measuring the spectral radiation component from the sun. The solar radiation data are given in Table 4 , in which column I gives the spectral range, and columns 2 and 4 give the spectral radiation components (a. m. and p. m.) of the sun (also of $\alpha$ Aurigæ, column 6) corrected for all losses except atmospheric absorption. The corresponding temperatures are given in columns 3,5 , and 7 .

TABLE 4.-Spectral Radiation Component of the Sun and of $\alpha$ Aurigæ in Per Cen of the Total.

\begin{tabular}{|c|c|c|c|c|c|c|}
\hline \multirow{3}{*}{$\begin{array}{l}\text { Spectral range. } \\
{[\mu=0.001 \mathrm{~mm}]}\end{array}$} & \multicolumn{4}{|c|}{ Sun. } & \multicolumn{2}{|c|}{$\alpha$ Aurigæ. } \\
\hline & \multicolumn{2}{|c|}{ a. m. } & \multicolumn{2}{|c|}{ p. $\mathrm{m}$. } & \multirow{2}{*}{$\begin{array}{l}\text { Spectral } \\
\text { radiatlon } \\
\text { compo- } \\
\text { nent. }\end{array}$} & \multirow[b]{2}{*}{$\begin{array}{l}\text { Temper- } \\
\text { ature. }\end{array}$} \\
\hline & $\begin{array}{c}\text { Spectral } \\
\text { radiation } \\
\text { component. }\end{array}$ & $\begin{array}{l}\text { Temper- } \\
\text { ature. }\end{array}$ & \begin{tabular}{c|} 
Spectral \\
radiation \\
component.
\end{tabular} & $\begin{array}{l}\text { Temper- } \\
\text { ature. }\end{array}$ & & \\
\hline 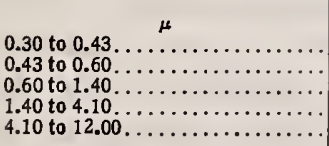 & $\begin{array}{r}25.0 \\
22.1 \\
31.8 \\
20.6 \\
.5\end{array}$ & $\begin{array}{r}{ }^{\circ} \mathbf{K} . \\
\mathbf{5}, 670 \\
6,500 \\
5,860 \\
6,060 \\
\ldots \ldots \ldots\end{array}$ & $\begin{array}{r}25.6 \\
19.0 \\
35.0 \\
20.1 \\
.8\end{array}$ & $\begin{array}{l}{ }^{\circ} \mathrm{K} . \\
5,750 \\
5,760 \\
5,050 ? \\
6,140\end{array}$ & $\begin{array}{r}18.4 \\
18.2 \\
30.6 \\
26.4 \\
6.4\end{array}$ & $\begin{array}{c}{ }^{\circ} \mathrm{K} . \\
\mathbf{5}, 000 ? \\
5,800 \\
6,000 \\
5,200 ? \\
\ldots \ldots \ldots \ldots\end{array}$ \\
\hline Average... & . & 6,000 & & 5,900 & & 5,900 \\
\hline
\end{tabular}

For the purposes of this investigation the agreement between the observed temperatures of $\alpha$ Aurigæ and the sun is satisfactory, and the scale of temperatures of stars remains as previously published. 
It is interesting to note that less than I per cent of the total solar radiation measured is of wave lengths greater than $4 \mu$. This is in agreement with measurements made by the Smithsonian Astrophysical Observatory showing that practically no solar radiation of wave lengths greater than $4 \mu$ is transmitted by the earth's atmosphere. From the foregoing measurements on planetary radiation it would appear that the absence of solar radiation of wave lengths greater than $4 \mu$ is partly owing to the fact that but little is emitted.

These data are interesting in showing a close agreement between the spectral radiation components of the sun and $\alpha$ Aurigæ in the visible spectrum ( 0.43 to $0.6 \mu$ ), which is in agreement with the visual and photographic observations. However, in the ultraviolet the radiation component of $\alpha$ Aurigæ is less, and in the infrared it is greater (owing partly to the low-temperature radiation from the companion star) than that of the sun. The lower value in the ultra-violet may be owing in part to the fact that the measurements on $\alpha$ Aurigæ were made through a larger air mass, and hence there was a greater amount of scattering of the incoming radiations. But this does not explain, and is inconsistent with, the higher values observed in the infra-red in many of the stars measured, in spite of the fact that the air mass was greater than for similar measurements on the sun. No doubt this is owing partly to experimental errors, but some of it is to be attributed to the low (selective) infra-red emission in the case of the sun, the earth's atmosphere being quite transparent to radiations greater than $7 \mu$.

In conclusion it is relevant to add a few comments concerning the relative size of the galvanometer deflections as observed with the 36-inch Crossley reflector and with the 40-inch Lowell reflector. The latter has a diagonal mirror which probably renders the two mirrors of not markedly different effective aperture.

For the I92 I observations the galvanometer coils were in series parallel, giving a resistance of $20 \mathrm{ohms}$ as compared with $5 \mathrm{ohms}$ in I9I 4. Hence a galvanometer sensitivity of $i=\mathrm{I} \times \mathrm{IO}^{-10}$ ampere was really only $i=2 \times 10^{-10}$ ampere when compared with the observations of I9I4. This reduced (by one-half) galvanometer sensitivity was compensated for by using the double deflection (by alternately exposing both thermojunctions to the star) and the resultant galvanometer deflections of 1921 for a given star are practically the same as those observed in rigr4.

WASHINGTON, September I2, 1922. 